\title{
Optic Neuritis in Farwestern and Midwestern Region of Nepal: A Hospital Based Study
}

\author{
Thapa $\mathrm{BB}^{1}$, Dhakal $\mathrm{Y}^{2}$
}

\begin{abstract}
Background: optic neuritis is a common cause of visual loss. Its demographic and clinical picture is different in the eastern and western countries. The treatment outcomes are also different in report from different place. Its data is lacking in the Midwestern and Far western Nepal. Objective: To report its clinical features, demographic pattern and response to treatment in the patients of this region. Materials and methods: The hospital based data of patients of Nepalgunj medical college were analyzed retrospectively with respect from September 2016 to June 2017. Results: Sixteen patients (20 eyes) were found to have optic neuritis (papillits in 13 and retrobulbar optic neuritis in 7 eyes). The male to female ratio was $1: 1.29$. The mean age of the patients was $27.63 \pm 12.48$ years ( $95 \%$ $\mathrm{Cl}=21.88-34.00)$. The most common modes of presentation was decrease in vision and color vision defect. One patient had multiple sclerosis at the presentation revealed by MRI with plaque in occipital cortex. Visual outcome was encouraging in all cases with pulse steroid therapy $(p=0.002)$. Conclusion: Pulse methylprednisolone therapy is found to have better prognostic results. In demographic pattern younger population is found more affected in our study than other reports.
\end{abstract}

Key Words: Optic neuritis, relative afferent pupillary defect, methylprednisolone

\section{INTRODUCTION}

Optic neuritis is a common cause of sudden visual loss with or without pain. It commonly affects young adults with male to female ratio of $1: 1.3^{1}$. Optic neuritis is divided into two types: typical and atypical. Typical optic neuritis is caused by either multiple sclerosis (MS) or idiopathic cause. Atypical optic neuritis is caused by inflammatory disease other than multiple sclerosis ${ }^{2}$. Typical optic neuritis is usually unilateral in adults but in case of children presents bilaterally. Racial and geographical difference in its occurrence is known. People of white race has better treatment outcome than that of black race ${ }^{3}$.

Recognition of this condition is important due to its association with multiple sclerosis. Proper initial therapy with corticosteroids or interferon has shown to halt or delay the onset of multiple sclerosis and causes speedy visual recovery. Moreover, there are reports that the existing evidenced based guidelines are not used by many neurologists and ophthalmologists because of their unawareness of the efficacy of the recommended treatment schedule $e^{4,5}$.

There are very few studies available on this subject from the eastern part of the world, particularly from Japan, Nepal, India, China and Singapore, which shows different demographic characteristics than those described in optic neuritis treatment

1. Dr. Bikram Bahadur Thapa

2. Dr. Yogesh Dhakal

Address for correspondence:

Dr. Bikram Bahadur Thapa

Department of Ophthalmology

Nepalgunj Medical College Teaching Hospital

Nepalgunj, Nepal

Email: drbbthapa@gmail.com trial (ONTT) or in literature from the western world ${ }^{1,3,4,6-8}$. There is lack of data on optic neuritis from Midwestern and Farwestern region of Nepal. We undertook this study to find out the demographic pattern, clinical characteristics and treatment outcome of optic neuritis presenting to the Department of Ophthalmology at the Nepalgunj Medical College, Nepalgunj, Nepal.

\section{METHODOLOGY}

The patients were hospitalized and treated with the diagnosis of optic neuritis from September 2016 to June 2017 at NGMC were followed up. These data were collected retrospectively and analyzed using SPSS software. Optic neuritis was diagnosed by the presence of acute decrease in visual acuity with defective color vision, painful eye movement and relative afferent pupillary defect (RAPD). The patients having the above features with swelling of optic nerve only on ophthalmoscopy were diagnosed as having papillits and those not having optic nerve swelling were diagnosed as having retrobulbar optic neuritis. The patients with the diagnosis of ischemic, toxic or hereditary optic neuropathy were excluded from the study. The patients with inflammatory retinal or uveal signs were also excluded. The patients having visual acuity of better than $6 / 12$ were not admitted at our institute and thus were excluded from the study.

Systemic history was obtained for multiple sclerosis and other systemic diseases. History was obtained for a previous episode of similar ocular ailment. Demographic features (age, gender, and race, season of presentation) and ocular complaints were noted in all cases. Ocular complaints enquired were ocular pain, headache and painful extra ocular movements.

Ocular examination included recording of best corrected visual acuity (using retinoscopy and Snellen's chart), color vision test 
(with Ishihara's pseudo isochromatic color vision chart), ocular movement were evaluated, swinging torch light test was done to record relative afferent pupillary defect (RAPD) and fundus evaluation under mydriasis with both direct and indirect ophthalmoscopy.

The patients with the diagnosis of optic neuritis had undergone neurological examination by an internist. Magnetic resonance imaging (MRI) was performed for all cases to confirm optic neuritis and rule out other diseases. Erythrocyte sedimentation rate (ESR), total and differential leucocytes counts and venereal disease research laboratory (VDRL) test for syphilis were also obtained before therapy. Perimetry was obtained using Automated Perimeter in eyes with visual acuity of at least $6 / 60$ during the initial presentation.

The patients were treated with pulse methylprednisolone therapy: intravenous methylprednisolone $1 \mathrm{gm} /$ day for 3 days diluted in $5 \%$ dextrose solution followed by an 11 days course of oral prednisolone. The patients who presented late, with profound loss of vision without any evidence of systemic precipitating factors were also treated with pulse steroids and were included in this study.

\section{RESULTS}

Between September 2016 and June 2017, we admitted 16 patients with the diagnosis of optic neuritis fulfilling the inclusion criteria. The age of the patients was ranged from 6 to 55 years and there was no significant gender difference ( $M: F=$ 1:1.29). Most of the patients belonged to the Terai region of Midwestern and Far western region. Most of our patients were of Chhetri tribe $(62.5 \%)$ and maximum cases were presented on summer season (43.75\%) (Table I).
Of the 16 patients, 4 (25\%) had bilateral involvement. One patient had a history of recurrent attacks (disc pallor was noted in the previously affected eye). Most of the patients (62.5\%) presented to the hospital after 1 week of onset of symptoms. The most common symptom was decrease in vision which was found in all patients. Other common symptoms were headache, eye pain and deviation of eye (Table II).

In the affected eyes visual acuity ranged from $6 / 18$ to no light perception. Visual acuity of less than $6 / 60$ was recorded in 11 eyes ( $55 \%)$, of which 4 eyes ( $20 \%$ ) were with visual acuity of no perception on light. Relative afferent pupillary defect (RAPD) was detected in all unilateral cases and two bilateral cases with asymmetrical visual acuity. While in two cases with bilateral disease there was no RAPD but had sluggishly reacting pupil. One child had exotropia detected on involved eye with visual acuity of no perception of light. $60 \%$ of cases had disc edema in the affected eye.

On investigating color vision by Ishihara's chart $80 \%$ eyes were total color blind and rest (20\%) were with red green deficiency. On MRI head and orbit perineural contrast enhancement on T1 images was seen in 10 eyes and in one case there was bilateral occipital lobe plaque confirming diagnosis of multiple sclerosis. 16 patients (20 eyes) received high dose intraveinous pulse steroid therapy for 3 days followed by oral steroid for next 11 day and then tapered. Following the treatment, there was improvement of symptoms in almost all eyes even in the eyes with no perception of light. The visual improvement was evident within 24 hour of first dose of intraveinous methylprednisolone.

\begin{tabular}{|c|c|c|c|c|c|}
\hline Age group & Number & Percentage & Mean & SD & $95 \% \mathrm{Cl}$ \\
\hline $\begin{array}{l}\text { Child } \\
\text { (0-14 year) }\end{array}$ & 3 & 18.9 & \multirow[t]{3}{*}{27.63} & \multirow[t]{3}{*}{12.45} & \multirow[t]{3}{*}{$21.88-34.00$} \\
\hline $\begin{array}{l}\text { Adult } \\
\text { (15-60 year) }\end{array}$ & 13 & 81.1 & & & \\
\hline Old $(>60)$ & 0 & 0 & & & \\
\hline \multicolumn{2}{|l|}{ Sex } & \multicolumn{2}{|l|}{ Number } & \multicolumn{2}{|c|}{ Percentage } \\
\hline \multicolumn{2}{|l|}{ Male } & \multicolumn{2}{|l|}{7} & \multicolumn{2}{|c|}{43.7} \\
\hline \multicolumn{2}{|l|}{ Female } & 9 & & \multicolumn{2}{|c|}{56.3} \\
\hline \multicolumn{6}{|c|}{ Ratio (M: F) $=1: 1.29$} \\
\hline \multicolumn{2}{|c|}{ Address } & \multicolumn{2}{|l|}{ Number } & \multicolumn{2}{|c|}{ Percentage } \\
\hline \multicolumn{2}{|l|}{ Midwestern } & \multicolumn{2}{|l|}{7} & \multicolumn{2}{|c|}{43.7} \\
\hline \multicolumn{2}{|l|}{ Farwestern } & \multicolumn{2}{|l|}{8} & \multicolumn{2}{|c|}{50.0} \\
\hline \multicolumn{2}{|l|}{ Indian } & \multicolumn{2}{|l|}{1} & \multicolumn{2}{|c|}{6.3} \\
\hline \multicolumn{2}{|c|}{ Geographical region } & \multicolumn{2}{|l|}{ No. } & & \\
\hline \multicolumn{2}{|l|}{ Hill } & \multicolumn{2}{|l|}{4} & \multicolumn{2}{|c|}{$25 \%$} \\
\hline \multicolumn{2}{|l|}{ Terai } & \multicolumn{2}{|l|}{12} & \\
\hline \multicolumn{2}{|l|}{ Race } & Number & & \multicolumn{2}{|c|}{$\begin{array}{c}75 \% \\
\text { Percentage }\end{array}$} \\
\hline Chhetri & & 10 & & 62.5 & \\
\hline Brahmin & & 1 & & 6.2 & \\
\hline Dalit & & 4 & & 25. & \\
\hline Magar & & 1 & & 6.2 & \\
\hline
\end{tabular}

Table I: Demographic characteristic 


\begin{tabular}{|c|c|c|c|}
\hline $\begin{array}{l}\text { Duration of illness before } \\
\text { presentation }\end{array}$ & Number & Percentage & \\
\hline Before 1 week & 6 & 37.5 & \\
\hline 1 week to 1 month & 6 & 37.5 & \\
\hline After 1 month & 4 & 25.0 & \\
\hline \multicolumn{2}{|l|}{ Laterality of disease } & Number & Percentage \\
\hline \multirow{2}{*}{ Unilateral } & Right eye & 6 & \multirow{2}{*}{75.0} \\
\hline & Left eye & 6 & \\
\hline Bilateral & Both eye & 4 & 25.0 \\
\hline Symptoms & Number & Eyes & Percentage \\
\hline Eye pain & 7 & 8 & 43.8 patient $/ 40 \%$ of eyes \\
\hline Headache & 4 & & $25 \%$ patients \\
\hline Deviation of eye & 1 & 1 & $7.5 \%$ patients \\
\hline Visual symptoms & 16 & 20 & $100 \%$ of eye \\
\hline
\end{tabular}

Table II: Presentation characteristic of patients

\begin{tabular}{|l|c|c|c|}
\hline Visual acuity & Presentation & Discharge & $\begin{array}{c}\text { Last } \\
\text { follow up }\end{array}$ \\
\hline$>/=6 / 18$, & 3 & 10 & 15 \\
\hline $6 / 24-6 / 60$, & 6 & 9 & 5 \\
\hline $6 / 60,-1 / 60$, & 4 & 1 & 0 \\
\hline HM-PL & 3 & 0 & 0 \\
\hline No PL & 4 & 0 & 0 \\
\hline
\end{tabular}

Table III: Visual acuity on presentation, discharge and 1 month follow up

All of the patients returned for follow-up visit at 1 month. Visual outcome was recorded better at one month follow up (Mean Log MAR VA of 0.41 ) as compare to initial presentation (Mean Log MAR VA of 1.37) significantly ( $p=0.002$ ) (Table III). Colour vision was also recorded better on follow up visits in all eyes. One patient had multiple sclerosis with plaque in both occipital lobe at presentation. These plaques were resolved after pulse steroid therapy. Neurological examination was within normal limits in all other cases. There were no patients with sinusitis.

\section{DISCUSSION}

Evaluation of optic neuritis requires a brilliant clinical detail, appropriate laboratory workup and imaging that provides correct etiological diagnosis. Thereafter treatment gives good outcomes and future trick for natural course $\mathrm{e}^{1,2}$.

There is only one published study on demography of optic neuritis from Nepal and it was done on eastern region ${ }^{6}$. The demographic characteristic like racial and cultural characteristics of eastern region are quite different from that of Midwestern and Farwestern region of Nepal.

In many aspects, this report is different from the reports of optic neuritis from other parts of the world. The mean age of

our patients was younger to that reported in Optic Neuritis Treatment Trial (ONTT), study from oriental countries as well as from eastern Nepal ${ }^{4,6-9}$. Females are reported to be involved more frequently in our study as seen in the ONTT by Beck et al.," whereas study from eastern world and eastern Nepal showed slight male preponderance ${ }^{4,6-8}$.

We found a high prevalence of the disease in patients belonging to the Terai region in contrast to the study by Das et al., ${ }^{6}$ who found more in hilly region of Nepal. This might be because of many cultural and geographical barriers are prevalent in the hilly part of this region.

We observed there is significantly high occurrence of disease in Chhetri. Such racial variation was already been showed by various studies including ONTT ${ }^{9}$. In our study most of the patient presented during summer season. Seasonal variation shown by this study might be by chance and need further study of longer duration. It has been reported that retro-bulbar optic neuritis is more common (65\%) in adults by ONTT, ${ }^{10}$ whereas we found more frequent occurrence of papillits in younger adults $(60 \%)$ as seen in the another study from eastern Nepal ${ }^{6}$ and Wang et al ${ }^{7}$ from Singapore(65\%) but Wakakura et al showed both retrobulbar neuritis (50\%)and papilitis (50\%)occurred equally ${ }^{4}$.

There was a high occurrence of bilateral optic neuritis in our study (25\%), which is lesser to that of study from eastern Nepal by Das et $\mathrm{al}^{6}(47.2 \%)$ but Wang et $\mathrm{al}^{7}(19 \%)$, showed lesser bilaterality. Most of our patients (62.5\%) presented after 1 week of onset of symptoms. Again, $25 \%$ of patients only present after one month of onset of symptom similar finding was shown by Das et al ${ }^{6}$ from eastern Nepal reflecting neglect and poor health status of Nepalese population. The presenting complaint in all the patients was visual impairment. Few 
patients also complained of eye pain and headache. Uhthoff's symptoms were not observed in any of our patients as seen in study by Das et al ${ }^{6}$.

Visual acuity in most of our patients was poor at the time of presentation. Fifty-five percent of the eyes had visual acuity of $<6 / 60$ at the time of presentation. There was high prevalence $(20 \%)$ of patients presenting with no light perception which is similar to finding of Das et al (22.2\%) although higher than that of any report published on optic neuritis. The ONTT study ${ }^{10}$ reported only $3 \%$ of patients presenting with no light perception. The reason may be that the patients in our part of the world generally seek ophthalmic consultation only when they are disabled due to poor visual acuity as well as unawareness about this disease.

Almost all of our eyes responded well to pulse methylprednisolone therapy, which is in accordance with the ONTT study report and the studies published from Japan, Singapore, China, India and Nepa ${ }^{3,4,6-10}$. Our study showed initial good outcome of the pulse steroid therapy in the Nepalese population of optic neuritis. The patients having initial vision of no light perception did well with pulse steroid therapy although final visual outcome was poorer than others as expected. However, in other patient final recovery of visual acuity was not related to the pretreatment visual acuity. Colour vision was improved in all cases. Few of the patient developed side effect in the form of weight gain due to steroid therapy. This showed delay reporting of the patient reduces the visual recovery.

Conversion rate to multiple sclerosis is not studied due to the short follow-up period. But one child was diagnosed to have multiple sclerosis on MRI at presentation. Longer and proper follow-up is required to find out the incidence of multiple sclerosis in these patients. Since this is a hospital-based study, there may be higher actual magnitude of the problem in the community. Longer prospective study will further elaborate about this entity in this remote part of Nepal.

\section{CONCLUSION}

The demographic and clinical characteristics of optic neuritis in Midwestern and Farwestern Nepal have some similarity with those reported from eastern Nepal, China, Japan and Singapore but different from those reported from the western world. Response to pulse methylprednisolone therapy is rapid and good in these patients. Even eyes with no perception of light respond to the pulse steroid therapy. Thus we recommend early diagnosis and administration of pulse steroid therapy for typical optic neuritis to have good visual prognosis.

\section{REFERENCES}

1. Bhatia R, Singhal A. Optic neuritis: A blurry issue. Neurol India 2012;60:459-60

2. Trobe J D. The neurology of vision. Oxford university press 2001; 202-236.
3. Pandit L, Shetty R, Misri Z, Bhat S, Amin H, Pai V et al. Optic neuritis: Experience from a south Indian demyelinating disease registry. Neurol India 2012;60:470-5

4. Wakakura M, Minei- Higa R, Oono $S$ et al. Baseline features of idiopathic optic neuritis as determined by a multicenter treatment trial in Japan. Jpn J Ophthalmol 1999;43:127-32.

5. Leueck CJ, Danesh-Meyer HV, Marqtie FJ et al. Management of acute optic neuritis: A survey of neurologists and ophthalmologists in Australia and New Zealand. J Clin Neurosci 2008;15:1340-5.

6. Das H, Gautam M, Lavaju P. An overview of idiopathic optic neuritis in eastern Nepal. Nep J Ophthalmol 2010;2(3):10-15

7. Wang J C, Tow S, M Med A T et al. The presentation, etiology, management and outcome of optic neuritis in an Asian population. Clin and Exp Ophthalmol 2001; 29:312-215.

8. Zhang X, Wang W, Wei W, Wang O, Wei Y, Kermode AG. Etiological profile of presumptive optic neuritis in China. J Clin Neurosci 2008;15:1346-9.

9. Beck RW, Trobe JD. What we have learned from the Optic Neuritis Treatment Trial. Ophthalmology 1995;102:1504-8.

10. Optic Neuritis Study Group. The clinical profile of optic neuritis. Experience of the optic neuritis treatment trial. Arch Ophthalmol 1991;109:1673-8

11. Brusaferri F, Candelise T. Steroids for multiple sclerosis and optic neuritis: a meta-analysis of randomized controlled clinical trials. J Neurol. 2000;247:435-42

12. Ray S, Gragoudas E. Neuroretinitis. Int Ophthalmolol Clin.2001; 41:83-102.

13. Hickman SJ, Dalton CM, Miller DH et al. Management of acute optic neuritis. Lancet 2002; 360:1953-62 